\title{
Current approach to diuretic resistance in heart failure
}

\author{
Hüsnü Değirmenci*, Eftal M Bakırcı and Hikmet Hamur \\ Department of Cardiology, Faculty of Medicine, Erzincan Binali Yıldırım University, Turkey
}

\begin{abstract}
Diuretics are one of the main drugs for heart failure, which is the leading cause of morbidity and mortality. It contributes to the reduction of symptoms and hospitalizations. However, diuretic resistance is seen in $20-30 \%$ of patients with heart failure. Various parameters such as weight loss, congestion status, urine output, urine sodium excretion is evaluated in determining diuretic resistance. Treatments such as restriction of salt and fluid intake, discontinuation of nonsteroidal antiinflammatory drugs, increasing diuretic dose and frequency, combination of diuretics from different classes, hypertonic saline infusion or dopamine infusion are used in diuretic resistance.
\end{abstract}

\section{Introduction}

Heart failure is seen in $1 \%$ of patients over 65 years old [1]. Heart failure is one of the leading causes of morbidity and mortality. Diuretics are among the main drugs used in this disease with high morbidity and mortality rates [1-2]. However, $20-30 \%$ of patients with heart failure have diuretic resistance. Diuretics reduce congestion and reduce hospitalizations [1]. Therefore, we present the current approach to diuretic resistance in heart failure in this article.

\section{Mechanisms of diuretic resistance}

Low systemic blood pressure, high blood urea nitrogen, ischemic heart failure and diabetes are predictors of diuretic resistance. Diuretics are ineffective in case of venous edema, lymphatic edema, and shifting of the intravascular volume to the third space. No sodium and fluid restriction, hepatic cirrhosis, hypoalbunemia, nephrotic syndrome, insufficient absorption, insufficient dosage of the drug, low frequency of drug intake, drug nonadherence, decreased diuretic secretion, insufficient kidney to the drug, use of nonsteroidal anti-inflammatory drugs, increased renin angiotensin aldesteron system activation causes diuretic resistance $[1,3]$.

\section{Definition of diuretic resistance}

$1 \mathrm{mg}$ bumetanide, $20 \mathrm{mg}$ torsemide and $40 \mathrm{mg}$ furosemide are equivalent. Congestion persists despite using furosemide over 80 $\mathrm{mg}$, weight change $<2.7 \mathrm{~kg}$ despite $40 \mathrm{mg}$ furosemide or equivalent diuretic, urine output $<1400 \mathrm{ml} /$ day despite using $40 \mathrm{mg}$ furosemide or equivalent diuretic, fractional excretion of sodium in basal $<0.2 \%$, a urinary sodium concentration / urinary furosemide concentration ratio of $<2 \mathrm{mmol} / \mathrm{mg}$ or a urinary sodium amount of $<90 \mathrm{mmol}$ despite 160 $\mathrm{mg}$ furosemide twice in 3 days is defined as diuretic resistance $[4,5]$.

\section{Treatment}

\section{Initial measures}

Daily sodium intake should be below $100 \mathrm{mEq} /$ day. Nonsteroidal anti-inflammatory therapy should be discontinued. The frequency and dosage of loop diuretics should be increased [1,5-7].

In hospitalized patients, $80 \mathrm{mg}$ intravenous loop diuretic or intravenous loop diuretic is started at 2.5 times the oral dose at home.
Urine sodium strategy (emergency pathway) for evaluating the diuretic response or urine output strategy (established pathway) can be used [2,5-7].

Spot urine sodium is checked 1-2 hours after the diuretic is started in the emergency pathway. If urine sodium is $>50-70 \mathrm{mmol} / \mathrm{l}$, urine sodium assessment is repeated after each dose. Current doses are repeated every 6-12 hours [2,5-7].

In the established pathway, urine output is evaluated 2-6 hours after the diuretic is started. If the urine output is above $150 \mathrm{ml} /$ hour, the current doses are repeated every 6-12 hours [2,5-7].

If spot urine sodium is $<50-70 \mathrm{mmol} / \mathrm{l}$ or urine output is $<150 \mathrm{ml} /$ hour, twice the previous dose is administered intravenous loop diuretic. In insufficient diuretic response, up to $300 \mathrm{mg}$ of furosemide and equivalent loop diuretics are repeated. Combination therapy is started in case of insufficient diuretic response. The first choice in combination therapy is to add a thiazide diuretic to the loop diuretic. The second preference in combination therapy is to add acetazolamide, amiloride or spironolactone to the loop diuretic [2,5-7].

\section{Advanced measures}

Hypertonic saline infusion improves diuresis and renal function while shortening hospitalization. The addition of dopamine infusion to low dose intravenous furosemide provides urine output similar to high dose diuretic [5-7].

\section{References}

1. Jardima IS, dos Santos LR, Araújoc I, Marques F, Branco P, et al. (2018) A 2018 overview of diuretic resistance in heart failure. Rev Port Cardiol 37: 935-945. [Crossref]

*Correspondence to: Hüsnü Değirmenci, Department of Cardiology, Faculty of Medicine, Erzincan Binali Yıldırım University, Turkey, E-mail: husnudr1982@gmail.com

Key words: heart failure, morbidity, mortality, diuretic resistance, diagnosis, treatment

Received: December 15, 2020; Accepted: December 22, 2020; Published: December 31, 2020 
2. Nayor M, Larson MG, Wang N, Santhanakrishnan R, Lee DS, et al. (2017) The association of chronic kidney disease and microalbuminuria with heart failure with preserved vs. reduced ejection fraction. Eur J Heart Fail 19: 615-623. [Crossref]

3. Hoorn EJ, Ellison DH (2017) Diuretic resistance. Am J Kidney Dis 69: 136-142. [Crossref]

4. Masella C, Viggiano D, Molfinoa I, Zacchiaa M, Capolongoa G, et al. (2019) Diuretic Resistance in Cardio-Nephrology: Role of Pharmacokinetics, Hypochloremia, and Kidney Remodeling. Kidney Blood Press Res 44: 915-927. [Crossref]
5. Felker GM, Ellison DH, Mullens W, Cox ZL, Testan JM (2020) Diuretic Therapy for Patients with Heart Failure. J Am Coll Cardiol 75: 1178-1195. [Crossref]

6. Mullens W, Damman K, Harjola VP, Mebazaa A, Brunner-La Rocca HP, et al. (2019) The use of diuretics in heart failure with congestion: a position statement from the Heart Failure Association of the European Society of Cardiology. Eur J Heart Fail 21: 137-155. [Crossref]

7. Brisco-Bacik MA, Ter Maaten JM, Houser SR, Vedage NA, Rao V, et al. (2018) Outcomes associated with a strategy of adjuvant metolazone or high-dose loop diuretics in acute decompensated heart failure: a propensity analysis. $J$ Am Heart Assoc 7: e009149. [Crossref]

Copyright: (C2020 Değirmenci H. This is an open-access article distributed under the terms of the Creative Commons Attribution License, which permits unrestricted use, distribution, and reproduction in any medium, provided the original author and source are credited. 